\title{
Redes de aprendizagem colaborativa: contribuiçăo da Educaçăo a Distância no processo de qualificação de gestores do Sistema Único de Saúde - SUS*
}

Maria Ligia Rangel-S1

Ana de Oliveira Barbosa ${ }^{2}$ Nicia Cristina Rocha Riccio ${ }^{3}$ Joseilda Sampaio de Souza ${ }^{4}$

\section{Introdução}

Este artigo discute a experiência do Curso de Especialização em Saúde Coletiva: concentração em Gestão Pública Municipal, realizado em uma Instituição de Ensino Superior (IES) em parceria com o Sistema Único de Saúde (SUS), na Bahia, para a qualificação de gestores municipais de saúde. São abordadas as estratégias pedagógicas ulitizadas para Educação a Distância (EAD), em um contexto de profundas mudanças sociais que requerem das IES a apropriação das Tecnologias de Informação e Comunicação (TIC) e a inovação de processos de ensino-aprendizagem.

A sociedade atual experimenta, em todos os âmbitos, uma série de transformações devidas à evolução das TIC, que cursa com velocidade crescente da produção e circulação da informação e coloca desafios à educação, em face de uma economia informacional que conforma a infraestrutura do mundo global, interconectando a "sociedade em rede", tal como descrita por Castells (1999). A globalização envolve: as comunicações, os mercados, os fluxos de capitais e tecnologias, a socialização e trocas de conhecimentos que impõem a dissolução de fronteiras. Vivencia-se um período de transição de uma realidade para outra: da formação histórica da sociedade do capitalismo industrial para outro tipo de organização social, que vem se delineando como uma sociedade em rede. Em todos os momentos se estabelecem diálogos entre o global e o local, a homogeneidade e a diversidade, a ordem e a desordem (Morin, 1998).

Tais características se constituem como desafios a requererem um novo posicionamento das organizações educacionais para fazerem frente à educação como processo individual e social, a partir de referências científicas e tecnológicas de caráter inter/transdisciplinar, multirreferencial e pluricultural, e reconhecendose o aluno como sujeito da aprendizagem (Fróes Burnham et al., 2007).

Neste cenário, diante da necessidade da formação de sujeitos na sociedade contemporânea, a educação enfrenta um duplo desafio: vencer a crise dentro das diversas modalidades de ensino e superar as carências de estudos e formação permanente dos sujeitos inseridos nos distintos postos de trabalho, em processo contínuo de reconfiguração das práticas profissionais. Nessa perspectiva, a EAD tem sido cada vez mais requisitada, no cenário nacional, como possibilidade de

\footnotetext{
- Texto resultante de experiência desenvolvida no Curso de Especialização em Saúde Coletiva: concentração em Gestão Pública Municipal, financiado pela Secretaria da Gestão do Trabalho e da

Educação na Saúde do Ministério da Saúde (SGTES/MS), e realizado em parceria com a Escola Estadual de Saúde Pública da Secretaria da Saúde do Estado da Bahia (EESP/

SESAB) e o Conselho Estadual dos Secretários Municipais de Saúde da Bahia (COSEMS/Bahia).

${ }^{1}$ Departamento de Saúde Coletiva I, Instituto de Saúde Coletiva, Universidade Federal da Bahia (ISC/UFBA). Rua Basílio da Gama $s / n^{\circ}$. Campus Canela. Salvador, BA, Brasil. 40.110-040. lirangel@ufba.br

${ }^{2}$ Secretaria Municipal de Saúde de Salvador. ${ }^{3}$ Centro de Processamento de Dados, UFBA. ${ }^{4}$ Bolsista, ISC/UFBA.
} 
educação, a contribuir com a superação da carência de formação em diversas áreas do conhecimento e a favorecer o acesso ao ensino nas regiões mais longínquas.

Entretanto, o termo EAD geralmente remete a uma modalidade de ensino orientada pelo conceito de sala de aula ampliada, em que a associação do tempo e espaço ultrapassa as barreiras do espaço físico e do tempo determinado. Ou seja, associa-se EAD diretamente a uma modalidade de ensino que utiliza processos de mediação tecnológica para ultrapassar a distância física. Contudo, as potencialidades da EAD podem surpreender positivamente os envolvidos nos processos - alunos e professores -, se estes experimentam a mediação tecnológica das atividades de ensino-aprendizagem orientada por algumas estratégias pedagógicas que valorizam os sujeitos, a intersubjetividade, a aprendizagem colaborativa, favorecendo a formação de comunidades de aprendizagem em todos os níveis.

Nesse sentido, dentre os desafios da EAD, destaca-se a noção de tempo e espaço, modificada no ambiente virtual, que passa a ter uma forte representação, pois define a relação de copresença entre professores e alunos no processo de aprendizagem. O curso a distância deve defini-lo, tal como acontece em uma instituição de ensino que tem endereço físico, local e tempo de referência para os participantes. Não se trata de uma estrutura física em uma instituição, como uma sala de aula, mas de um ambiente virtual de aprendizagem, a ser frequentado com regularidade durante um tempo preestabelecido. Assim, no curso a distância, o endereço é o virtual e o acesso se dá mediante a identificação do aluno ou professor e senha, tendo definido um período de duração, com previsão de início e término, ou seja, redefinindo-se na noção atemporal da rede.

Ademais, nesse cenário de EAD, um dos elementos essenciais é a comunicação, pois, com o avanço das tecnologias, a utilização de novos recursos comunicacionais na EAD torna-se cada vez mais viável, facilitando o acesso à informação em tempo real, de forma globalizada e irreversível. Entretanto, pressupõe-se uma comunicação interativa, pois é através da interação/interatividade que se fortalece o processo de ensino e aprendizagem. Enfatiza-se, então, um modelo de EAD online associado a uma concepção metodológica orientada para a interação e a construção do conhecimento de forma colaborativa, em que se reconhece o aprendente como sujeito do seu processo de aprendizagem e estimula-se a atividade educativa em rede, onde não existe um centro fixo, mas sim centros móveis que se alternam durante todo o processo.

No contexto atual de educação, as tecnologias da informação e comunicação ampliam a ação da $E A D$, intensificando o processo de ensino-aprendizagem. Ressaltam-se características, como a autonomia e autoria por parte dos sujeitos envolvidos, que são imprescindíveis nos processos de EAD, haja vista as necessidades desses atributos na sociedade contemporânea, especialmente quando se trata de gestores públicos de saúde responsáveis pela liderança em processos decisórios participativos. A interlocução entre os sujeitos, os ambientes e as tecnologias pode favorecer o desenvolvimento desses aspectos, fomentando-se a interatividade a partir dos ambientes virtuais de aprendizagem, trabalhada de modo a potencializar atividades com práticas colaborativas, com espaços de escritas hipertextuais, e que tem se destacado de forma significativa na educação online.

Segundo Lévy (1999), a interatividade pode ser compreendida como a possibilidade de os sujeitos participarem ativamente, interferindo no processo com ações, reações, intervindo, tornando-se receptor e emissor de mensagens que ganham plasticidade, permitindo sua transformação imediata. Em outras palavras, a interatividade cria novos caminhos, novas trilhas, novas possibilidades, fazendo valer os processos e as escolhas dos sujeitos. Além disso, o trabalho educativo de uma perspectiva da interação, da participação, da troca, conduz à superação da lógica que percebe as tecnologias apenas como instrumentos e/ou ferramentas. Ao contrário, a existência das tecnologias nesse contexto educacional, seja ela presencial ou a distância, precisa ser compreendida na/para a educação; para além de meras ferramentas adicionais ou meras animadoras dos tradicionais processos de ensinar e aprender, pois, ao adotarmos essa lógica instrumentalista, teremos, como resultados, a educação tal qual está, revestida de recursos tecnológicos novos e avançados (Pretto, 1996). Outra possibilidade é que tal incorporação se dê como elemento fundante das transformações vivenciadas na contemporaneidade. Assim, as tecnologias passam a fazer parte do processo de ensino e aprendizagem como um elemento carregado de conteúdo, visando o fortalecimento das culturas e dos valores locais. 
As TIC introduzem um novo sistema simbólico que reorganiza "a visão de mundo de seus usuários, impondo outros modos de viver, pensar e agir, modificam hábitos cotidianos, valores e crenças, constituem-se em elementos estruturantes das relações sociais" (Bonilla, 2005, p.32), caracterizando-se como potencializadoras de processos de construção do conhecimento e práticas educativas que propiciam a autonomia e a emancipação dos sujeitos envolvidos.

Tais processos formativos e de capacitação são demandados em diversas áreas, destacando-se a saúde, frente aos desafios de construção do SUS, que, ao longo dos seus vinte anos, tem buscado preencher as lacunas de formação e desenvolvimento de trabalhadores do setor. Na área da saúde, a Educação Permanente em Saúde surge como uma necessidade da formação dos profissionais do sistema, orientada para o trabalho, também este reconfigurado pela nova sociedade (Davini, 2009; Ribeiro, Motta, 1999).

O processo de gestão do SUS apresenta-se como um grande desafio, quando a principal estratégia adotada para a reorientação do sistema é a descentralização, levando os gestores a enfrentarem pontos de estrangulamento para a sua efetivação, como: o financiamento, a reversão do modelo de atenção, a efetivação do controle social, a capacidade gerencial do sistema e de programas de saúde, entre outros aspectos. A gestão do SUS requer transferência de valores financeiros, materiais e simbólicos, bem como, a criação de uma tecnoestrutura estatal permeada por um intenso processo de negociação intergestores, e destes com os profissionais de saúde e comunidade. Assim, a capacitação dos gestores de saúde é percebida como uma necessidade para se ampliarem as possibilidades de fortalecimento do SUS e viabilizar sua construção, na direção da observância dos princípios e diretrizes que o orientam. Nesse sentido, a qualificação do pessoal de saúde permite aprofundar a experiência de difusão e apropriação de conhecimentos e informações em um país que vive, atualmente, um processo de grande desenvolvimento científico e tecnológico, ocupando o primeiro lugar na América Latina na produção de conhecimento, o que, sem dúvidas, é uma condição para se produzir a efetiva melhoria dos índices de saúde da população brasileira.

É nesse contexto que, frente à necessidade de facilitar o acesso à informação e ao conhecimento a gestores, profissionais, conselheiros, estudantes e cidadãos na área da Saúde Pública e Coletiva, desde 2005, no Instituto de Saúde Coletiva da Universidade Federal da Bahia (ISC/UFBA), se desenvolve o Projeto Net-Escola de Saúde Coletiva. Trata-se de um espaço de construção de informações e conhecimentos, aberto à construção colaborativa de conhecimentos em saúde na rede, pretendendo-se contribuir com a construção de saberes para a formação da consciência cidadã com respeito à saúde, bem como contribuir no fortalecimento do processo de contrução do SUS. Através de um sítio na internet, articulado a um ambiente virtual de aprendizagem, o Modular Object-Oriented Dynamic Learning Environment - Moodle, buscam-se realizar processos de aprendizagem colaborativos, respeitando-se a autonomia de pessoas, grupos e instituições na definição de suas necessidades. Assim, experimentam-se múltiplas possibilidades de formação e socialização do conhecimento para os diferentes públicos, seja através de um simples acesso à informação de uso imediato, ou mediante processos formais de educação permanente.

Para o relato da experiência do Curso de Especialização em Saúde Coletiva: Concentração em Gestão Pública Municipal, adota-se uma posição autorreflexiva, a fim de se analisarem os desafios colocados à equipe executora, tendo em conta os referenciais teórico-metodológicos que orientam o projeto de EAD da Net-Escola.

Apresenta-se, a seguir, uma breve explanação da estrutura do curso e dos principais tópicos que suscitaram a reflexão acerca das potencialidades das estratégias pedagógicas formuladas e praticadas, a partir do quadro de referências, tendo em conta as peculiaridades do público participante. Os resultados analisados foram extraídos dos registros contínuos no ambiente Moodle e de relatórios técnicos parciais e de final do curso, incluindo a enquete realizada ao final do mesmo com cursistas e professores-tutores. 


\section{Educação a distância na saúde: a experiência de um curso de especialização}

O Curso de Especialização em Saúde Coletiva: concentração em Gestão Pública Municipal teve como objetivo qualificar a atuação de gestores e equipes gestoras na gestão municipal de sistemas e serviços de saúde, conforme os princípios e diretrizes do SUS e mediante um projeto integrado com a Secretaria de Saúde do Estado da Bahia, através de sua Escola Estadual de Saúde Pública (EESP/SESAB), com o apoio do Conselho de Secretários Municipais de Saúde (COSEMS/BA).

O curso também objetivou contextualizar as políticas públicas de saúde no Brasil e o processo de construção do SUS, assim como analisar: os problemas e desafios do SUS na esfera municipal; as formas de organização da atenção à saúde na esfera municipal; os problemas da gestão do SUS e formas de enfrentamento; a gestão do SUS a partir do seu contexto político-normativo; as estratégias para a organização dos Sistemas Municipais de Saúde na perspectiva da regionalização - pactos solidários entre os municípios, dentre outras. Além desses objetivos, incorporou-se, nesse contexto formativo, a discussão do papel do gestor na condução da política municipal de saúde, instrumentalizando-o para o manejo das fontes e otimização dos recursos financeiros, materiais e simbólicos; promover o intercâmbio de experiências entre os gestores/gestores, gestores/equipes, equipes/equipes (Universidade, 2010).

O curso teve carga horária de 360 horas, com realização de seis encontros presenciais obrigatórios, entre os meses de fevereiro de 2009 a março de 2010; composto de sete Unidades de Aprendizagem, sequenciadas, exceto a Unidade de Metodologia, oferecida de modo transversal. Através do ambiente virtual de aprendizagem Moodle da UFBA, desenvolveu-se uma formação em nível de especialização com cento e cinquenta vagas para gestores municipais de saúde e suas equipes.

Foram selecionados 166 candidatos $(67,2 \%)$ do total de 247 inscritos, cujo perfil pode ser observado no Gráfico 1.

Gráfico 1. Perfil dos candidatos selecionados para o Curso de Especialização em Saúde Coletiva: concentração em Gestão Pública Municipal. Instituto de Saúde Coletiva, Universidade Federal da Bahia, 2009.

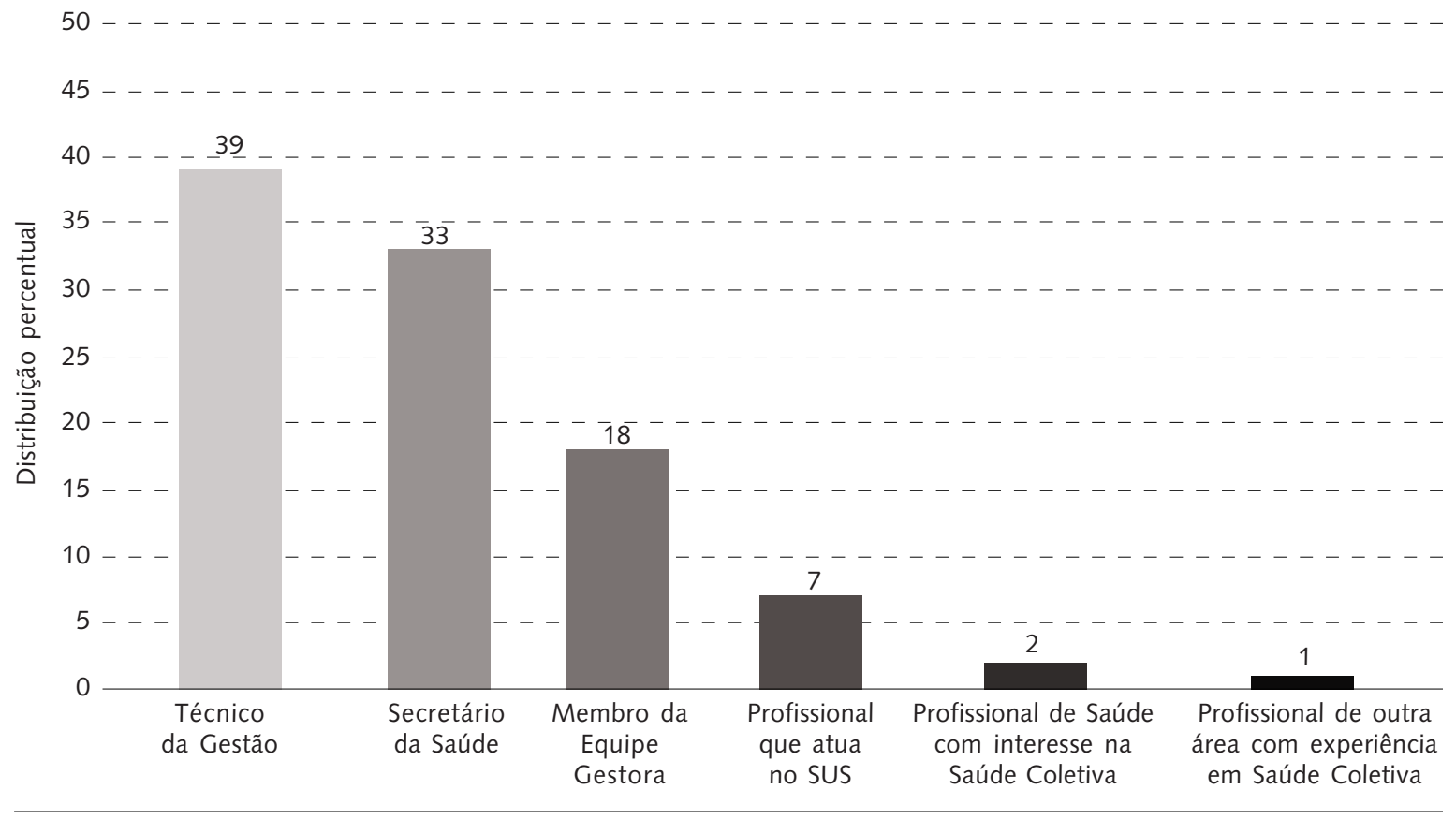

Fonte: Registros do processo seletivo do curso. 
Ressalta-se o fato de que 39\% dos candidatos selecionados eram técnicos que atuavam na gestão municipal, $7 \%$ profissionais que atuavam no SUS e 3\% profissionais com experiência e/ou interesse na área de Saúde Coletiva. O Gráfico 2 mostra o vínculo trabalhista dos participantes.

Gráfico 2. Distribuição percentual do tipo de vínculo trabalhista do cursista com o Sistema Único de Saúde. Instituto de Saúde Coletiva, Universidade Federal da Bahia, 2009.

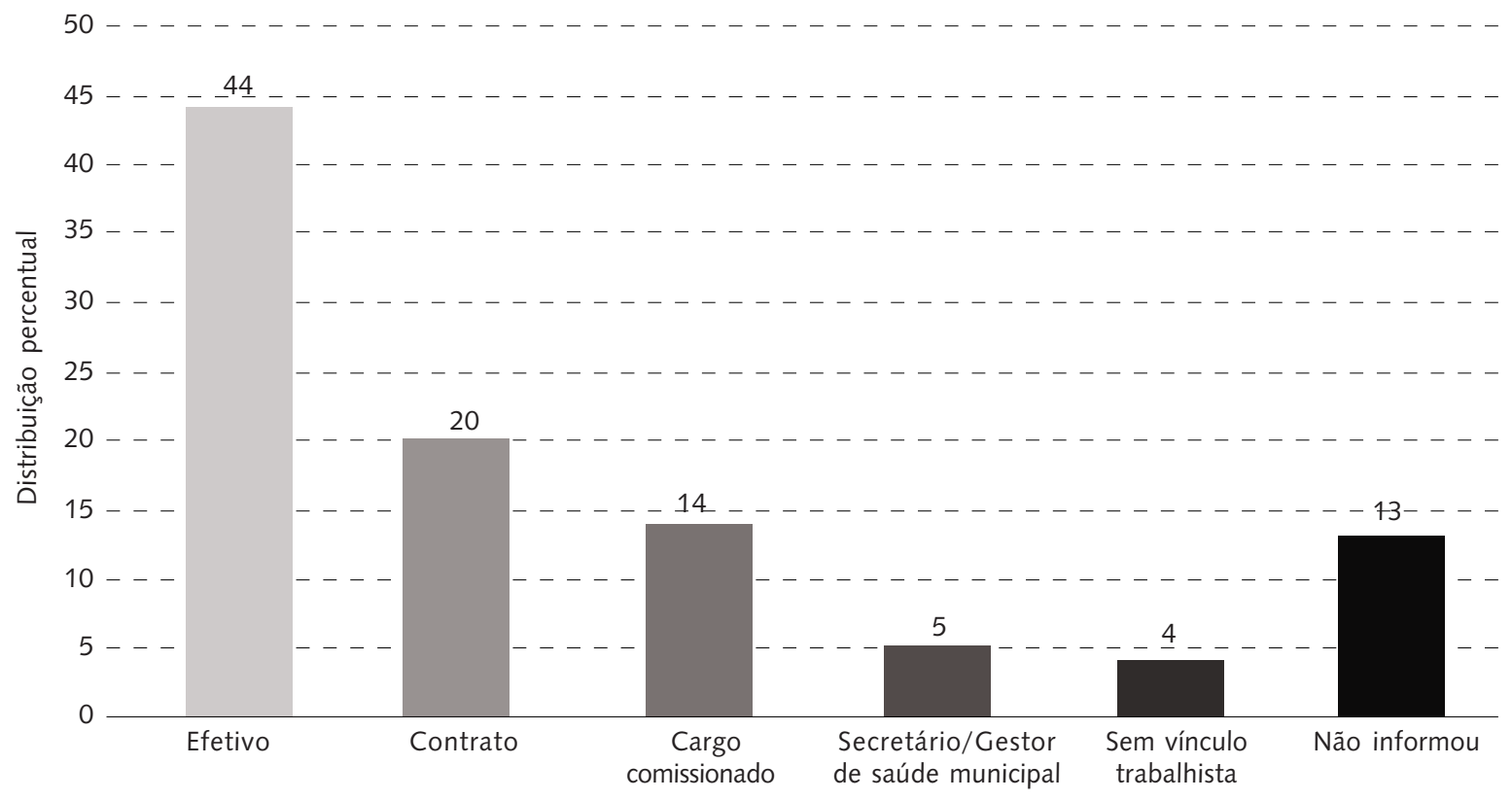

Fonte: Instrumento da avaliação do curso

O curso foi oferecido em estrutura modular progressiva, com ênfase "na dimensão do saber/fazer que conformou as práticas do curso, delineadas o mais próximo possível das condições reais dos sistemas e serviços onde os alunos/gestores atuavam" (Universidade Federal da Bahia, 2010, p.12), buscando estimular "a emergência de novos atores, os sujeitos coletivos de uma gestão municipal orientada para a universalidade, equidade e integralidade da atenção à saúde no SUS" (Universidade Federal da Bahia, 2010, p.12).

Buscou-se favorecer a possibilidade de se compreenderem e discutirem as situações vivenciadas pelos gestores e suas equipes, através de suas ações do cotidiano articuladas com as discussões teóricas, na perspectiva de comunidades de aprendizagem em rede. A rede passou a ser estruturante na organização e desenvolvimento metodológico do curso, uma vez que as atividades a distância aconteceram de forma integrada às atividade presenciais. Ademais, o Moodle, através das estratégias pedagógicas propostas durante o curso, constituiu-se num ambiente e espaço de interação direta entre os participantes, os professores e a equipe de coordenação, caracterizado por uma comunicação todos-todos.

Para a organização dos estudos, os cursistas foram divididos em sete grupos de aprendizagem identificados pelas macrorregiões em que trabalhavam, de modo a compartilharem experiências em contextos similares. Articulado a essa dinâmica, cada grupo contava com um professor-tutor que provocava e orientava as discussões e estudos, além de exercer um importante papel de acompanhar 
todo o desenvolvimento do curso, incentivando a participação e o aproveitamento dos cursistas. Cada professor-tutor, através da proposta de interação e das atividades do curso, valorizava, em todos os momentos, a articulação teoria e prática. Assim, nas unidades de aprendizagem, enfatizava-se a dimensão do saber/fazer, considerando-se as condições concretas do trabalho nos sistemas e serviços de saúde onde os alunos/gestores atuavam, estimulando-se o envolvimento de suas equipes no processo formativo. Vinculados a cada unidade de aprendizagem, aconteciam os encontros presenciais, em que as discussões eram aprofundadas, retornando-se à rede com o objetivo de se estabelecerem outras conexões.

\section{Desafios enfrentados no cotidiano do curso}

Dentre os desafios enfrentados no curso, destacam-se aspectos do contexto regional da gestão municipal de saúde e as limitações de acesso à rede de computadores na região. No estado da Bahia, questões do processo de construção do SUS local e regional ressoaram ao interior do curso, em especial o esforço da descentralização, adotada como principal estratégia para a reorientação do sistema. Os gestores enfrentavam pontos de estrangulamento, tais como mecanismos de transferência de valores financeiros, materiais e simbólicos, que os levavam a se envolverem em permanentes processos de negociação, em face da criação de uma tecnoestrutura estatal em desenvolvimento. Essas situações foram tornadas questões abordadas no interior do curso, em torno dos grandes temas previamente definidos: financiamento; modelo de atenção; planejamento e programação em sistemas e serviços de saúde; tecnologias de gestão; além de temas da atualidade discutidos em uma unidade específica que abordava o problema da violência; mídia e comunicação em saúde; saúde ambiental; sistemas de informação e saúde. Estes temas foram discutidos e trabalhados dentro do curso, quando os gestores eram estimulados, de modo interativo, a construírem soluções para enfrentar os problemas da gestão em seus municípios, tendo, como foco, os conteúdos das unidades.

As limitações de acesso à rede expressaram-se nas dificuldades de conectividade que surgiram em função da necessidade de acesso à internet para o bom desempenho dos cursistas. Contudo, essas dificuldades de acesso às TIC são compatíveis com o que ocorre no cenário nacional, que ainda preserva imensas lacunas de acesso, a despeito da indiscutível ampliação do uso da internet no Brasil. Segundo dados da pesquisa sobre o uso das TIC no Brasil, publicada pelo Comitê Gestor da Internet no Brasil (Comitê Gestor da Internet no Brasil, 2009), apenas 20\% dos domicílios urbanos estão conectados à rede, em contraste com apenas $4 \%$ dos lares da área rural. Tais dados mostram que o serviço de acesso a internet ainda é precário frente às necessidades dos brasileiros, especialmente daqueles que residem na área rural, seja pelo seu alto custo, seja pela indisponibilidade do serviço. Assim, problemas relacionados à indisponibilidade da rede ocorreram com vários participantes da gestão em saúde de vários municípios baianos, sobretudo aqueles mais afastados dos grandes centros urbanos, de modo que os cursistas se conectaram de locais variados.

Vê-se, no Gráfico 3, que: 46,7\% dos cursistas acessaram a internet em suas próprias residências, $40,7 \%$ em seu local de trabalho, 7,2\% em lan houses, 2,7\% em instituições de ensino e outros. Apesar das dificuldades, evidenciou-se o compromisso pela busca da formação por parte de muitos alunos, que criaram estratégias para participarem do processo de comunicação e interação do curso, às vezes deslocando-se do seu município para um outro próximo que oferecesse maior facilidade de conexão. Nesse sentido, a escolha do fórum como principal ferramenta de comunicação do curso foi acertada, pois este favoreceu a participação, uma vez que esta se dava de modo assíncrono, permitindo aos cursistas entrarem no ambiente virtual de aprendizagem (AVA) no momento em que conseguissem acesso à internet, e participarem das discussões, posto que estas permanecem registradas no ambiente. Contudo, o desenho do curso demandava, de cada aluno, o esforço de participação não apenas para "cumprir uma tarefa", mas para interagir com os demais, colocando suas questões do cotidiano de trabalho relacionadas ao tema em discussão, despertando o seu interesse e compromisso com a formação e a construção do conhecimento, baseada na solução de problemas. 
Gráfico 3. Local de acesso a internet segundo os cursistas. Instituto de Saúde Coletiva, Universidade Federal da Bahia, 2009.

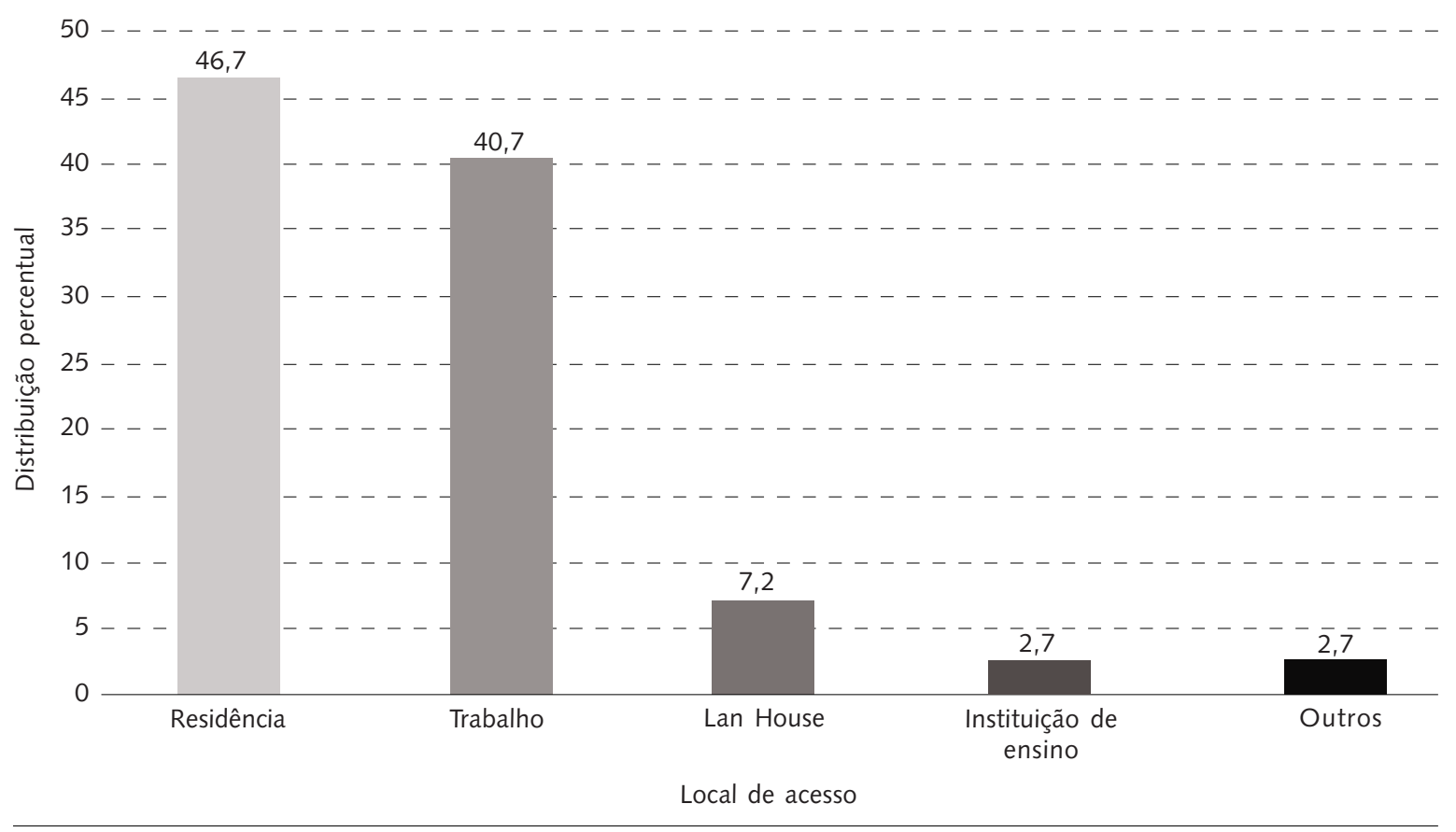

Fonte: Instrumento da avaliação do curso

\section{Liberdade de conhecer e modelo de participação}

A abordagem pedagógica do curso buscou estimular a autonomia do cursista em seu processo de aprendizagem, de modo coerente com as características da sociedade contemporânea. Estas, segundo Belloni (2003), se referem: à maior complexidade, maior incorporação de tecnologias, compressão espaço-tempo, maior responsabilidade com o trabalho, vínculos precários, maior mobilidade, exigência de multicompetência, capacidade de gerir situações em grupo, de se adaptar a situações novas, pronta disponibilidade para aprender, conformando um trabalhador mais informado e mais autônomo. Assim, a aprendizagem autônoma, o processo de ensino-aprendizagem centrado no aprendiz, aproveitando-se as experiências como recursos do aprendente, assim como o próprio professor, implica a conformação de seres autônomos, gestores de seu próprio processo de aprendizagem, capazes de regular esse processo. Isso requer do aluno maturidade e um mínimo de habilidade de estudo, o que se contrapõe ao que habitualmente se encontra entre os estudantes de EAD, em muitas experiências em que "os estudantes a distância tendem a realizar uma aprendizagem passiva, "digerindo pacotes institucionais" e "regurgitando" os conhecimentos assimilados nos momentos de avaliação" (Belloni, 2003, p.40).

Segundo Belloni (2003), o conceito de estudante autônomo é ainda embrionário e este é ainda uma exceção no âmbito das universidades abertas e convencionais. Contudo, situações devem ser criadas para encorajar essa aprendizagem que "propicie e promova a condição do conhecimento", considerando este como um processo, e não como uma mercadoria a ser consumida (Belloni, 2003, p.41).

Digerir/assimilar conteúdos e conhecimentos é diferente de atribuir significados e poder aplicá-los. O processo educativo que quer mais que levar o estudante a digerir conhecimentos deve se preocupar em criar espaços e estímulos para que os processos de atribuição de sentidos e de apropriação ocorram, tendo por referência a prática cotidiana do trabalho. Mas, são dificuldades para a autonomia do 
aprendizado: a capacidade de gestão do tempo; o planejamento; a autodireção e a automotivação. No sentido de superar essas dificuldades, a dimensão socioafetiva, mediante estratégias de contato e interação permanente com os estudantes, é mais importante que sistemas de avaliação e de produção de materiais (Belloni, 2003).

Nesta experiência, desde as primeiras unidades de aprendizagem, estimulou-se a liberdade de conhecer e experimentar todas as possibilidades de diálogo, compartilhando conhecimentos e opiniões coletivamente, através dos grupos, interagindo com os tutores e com os demais colegas, e construindo uma organização colaborativa que possibilitasse a multiplicação de ideias e a constituição de sentidos para articular os temas trabalhados com/e na gestão municipal.

Embora bem-sucedido, ressalta-se que esse processo formativo não foi homogêneo, uma vez que a diversidade de experiências deu lugar a questionamentos, reflexão, reconstrução de concepções e construção de conhecimentos, em um espaço sociocultural dantes não vivenciado por grande parte dos cursistas. Evidenciou-se um processo complexo, que exigiu tempo para aceitação e apropriação por parte dos cursistas, seja para o uso das TIC, seja da aceitação em participar da dinâmica que se pretendia imprimir ao processo de apendizagem. Assim, é possível que alguns cursistas tenham abandonado o curso por não se identificarem com a concepção de educação a distância, que enfatizava a interatividade e a participação ativa. Ademais, na dinâmica de aprendizagem desenvolvida, o lugar do professor-tutor pode ter causado estranhamento para uma geração que foi educada na concepção de que "o professor era o sábio e deveria transmitir conhecimento aos alunos, que agradecidos, tinham que anotar as palavras do sábio e reproduzí-las em exames" (Tapscoot, 2010, p.160). Tal recusa dos cursistas é, portanto, compreensível, ao adentrarem um novo contexto de aprendizagem que causa certa incerteza e requer a disposição para romper com modelos de processos formativos já instituídos. Entretanto, sabe-se que, para superarem a lógica tradicional de aprendizagem, é necessário que os sujeitos tenham uma plena participação, posicionando-se e expressando-se para um grupo, de forma a contribuírem com o processo de aprendizagem coletiva e em rede.

Analisando a atuação dos alunos, é possível afirmar que, aproximadamente, 16\% dos cursistas chegaram ao final do curso apresentando algum estranhamento com o modelo de participação, e muitos destes não conseguiram se sentir à vontade para realizar seus estudos através do ambiente virtual. Entretanto, vários alunos superaram a fase do estranhamento, alcançando certa autonomia para ousar, criar, questionar, embora às vezes se limitassem apenas a responder o que era questionado. De forma heterogênea, nesse mesmo cenário, houve um grande envolvimento dos alunos participantes ao apresentarem as demandas de seus municípios, articulando sua gestão com os estudos, mostrando a repercussão do curso nos seus espaços profissionais, mostrando-se mais seguros nas decisões da gestão, trazendo ferramentas adequadas para desenvolver ações. Portanto, revelou-se, através dos relatos dos alunos, seja no próprio ambiente virtual, seja nos encontros presenciais, que a dinâmica do curso fluiu de dentro para fora, ressaltando-se o importante papel dos professores-tutores.

A construção do conhecimento e a troca em cada grupo favoreceram a aprendizagem na diversidade de opiniões, a partir de uma ética do discurso pautada na argumentação e no diálogo. Além disso, pode-se considerar que o desejo de aprender e a participação de cada aluno dentro do curso foram fundamentais para desencadear a tessitura da rede, aproximando-se de processos de inteligência coletiva, como vislumbra Lévy (1999), em uma nova relação com o saber.

Assim, destaca-se que o acesso e a interação no ambiente foram condições indispensáveis para o rendimento acadêmico de cada aluno nas unidades. No sentido de propiciar maior interatividade no processo ensino-aprendizagem, priorizou-se a utilização de recursos como: fóruns temáticos, de integração, e fóruns de atividades de grupo; atividade de envio de arquivos, dentre outros recursos que foram utilizados em cada unidade, de acordo com a necessidade e proposta pedagógica.

Internamente, o curso apresentou um movimento ininterrupto, fluido e integrado, de interação e participação entre os professores-tutores, entre estes e a coordenação do curso, entre os próprios colegas, numa dinâmica de socialização e discussão, articulando a teoria e a prática com os problemas de gestão encontrados em cada município. O trabalho educativo no interior desse movimento mostrouse um grande desafio, sobretudo, para aqueles alunos que não tinham a vivência da participação na educação online, ou seja, a experiência da conexão via internet, de serem autores e colaboradores do 
seu processo de aprendizagem. Segundo Dias (2001), a cultura de participação interativa se "desenvolve quando todos os membros do grupo, incluindo o professor, se encontram num esforço conjunto" (Dias, 2001, p.25), em que a noção de participação está implicada no pensamento, no discurso, no saber e no aprender, realizando, assim, processos de imersão nos contextos de construção do conhecimento.

Destaca-se, ainda, que muitos alunos precisavam ter a fala ou direcionamento do professor-tutor para começarem a dialogar. Hipoteticamente, o modelo em que o professor é o centro pode dar mais segurança ao gestor/aluno, porém a estabilidade e a previsibilidade em que tal prática se sustenta não condizem com a ação de gestores, que precisam tomar decisões perante equipes e políticas de saúde do seu município. Nesse sentido, o modelo de EAD proposto configurou-se como uma estratégia de aprendizagem adequada para este público, ao deslocar o professor do centro, e dar lugar ao aluno como agente de seu processo de aprendizagem, estimulando-o à tomada de decisão e à autonomia da ação. Além disso, na educação online, o processo de construção do conhecimento compreende a interação entre pares, a cooperação, a colaboração, "salientando a mudança de foco na interação professor-aluno para as relações entre os membros do grupo" (Dias, 2001, p.32). O aluno/aprendente constrói o conhecimento no quadro de um processo social que se desenvolve na comunicação com os outros.

O envolvimento e a participação dos alunos/gestores na dinâmica do curso a distância trouxe, através do diálogo ativo no ambiente virtual, a possibilidade de socialização dos mais diferentes contextos. Mas, embora todos parecessem compreender que o acesso e a participação no ambiente virtual era condição necessária para a troca de conhecimentos e informações, a participação interativa, a comunicação, com o necessário envolvimento de todos, a superação do modelo tradicional de educação a distância de cunho transmissional, dominante na sociedade, foi um desafio. Os alunos se depararam com o convite à interação, marca fundamental nessa experiência que tentava estabelecer uma rede de múltiplas representações e interpretações, substituindo, assim, a lógica das representações singulares. Nessa perspectiva, valorizou-se o desempenho colaborativo, cabendo ao professor-tutor, a cada mensagem, a cada participação, buscar que os alunos questionassem suas ideias e concepções, encorajando-os a desenvolverem processos interativos e "provocativos" na construção do conhecimento.

Ademais, foi necessário enfrentar o desafio da escrita, cabendo aos professores-tutores lidarem com os medos e inseguranças dos alunos e estimularem a expressão pela escrita, de modo que os mesmos se autorizassem com seus textos, reconhecendo-se como autores, capazes de recriarem os conhecimentos a partir de suas experiências, e em contato com os textos dos colegas e dos autores das referências bibliográficas indicadas. Isso implicava a autoexposição, o que não parecia ser confortável para muitos. Contudo, só através desta estratégia é possível revelar, no ambiente virtual, a apropriação dos conteúdos pelo cursista, que passa a produzir uma forma própria de interação, expressão e organização textual, contextualizado localmente às demandas advindas no seu cotidiano de gestão do trabalho, articulado com os subsídios teóricos e normativos a que se referem suas ações, e em sintonia com a perspectiva da estrutura pedagógica do curso.

\section{Considerações finais}

O uso e a apropriação das tecnologias educacionais são, sem dúvida, uma demanda e uma necessidade da sociedade no processo de qualificação dos sistemas e serviços de saúde. O avanço das tecnologias de informação e comunicação vem repercutindo nos modos do agir humano, desde a construção do saber até as relações entre ciência, educação, sociedade e trabalho. A busca de alternativas para oferecer educação articulada ao contexto, e de largo alcance, desafia a experimentação de possibilidades metodológicas e organizacionais dos processos de ensino-aprendizagem que fortaleçam as iniciativas individuais e coletivas com enfoque nas soluções dos problemas do cotidiano do processo de construção dos sistemas de saúde. Na demanda por formação, a EAD ganha novas dimensões, especialmente ao articular as potencialidades e possibilidades das tecnologias digitais para os processos de formação e de disseminação de informações e conhecimentos. É certo que os ambientes virtuais e interativos de aprendizagem oferecem novas possibilidades, mas também trazem grandes 
desafios para se pensarem os processos formativos e de capacitação. Ao se tratar da construção de redes de aprendizagem colaborativa, através de processos de aprendizagem, pode-se afirmar, a partir da experiência relatada, o potencial da Educação a Distância, desenvolvida mediante um modelo aberto à participação e, sobretudo, convidativo à interatividade e à autonomia dos sujeitos.

\section{Colaboradores}

Os autores trabalharam juntos em todas as etapas de produção do manuscrito.

\section{Referências}

BELLONI, M.L. Educação a distância. Campinas: Autores Associados, 2003. (Coleção educação contemporânea).

BONILLA, M.H.S. Escola aprendente: para além da sociedade da informação. Rio de Janeiro: Quartet, 2005.

CASTELLS, M. A era da informação: economia, sociedade e cultura - a sociedade em rede. São Paulo: Paz e Terra, 1999. v. 1.

COMITÊ GESTOR DA INTERNET NO BRASIL. Pesquisa sobre o uso das Tecnologias da Informação e da Comunicação no Brasil: TIC domicílios e TIC empresas 2008.

Disponível em: <http://hal.ceptro.br/cgi-bin/indicadores-cgibr-

2008? pais $=$ brasil \&estado $=$ ba\&academia $=$ academia\&age $=$ de $-25-a-34-$

anos\&education $=$ pos-mestrado\&purpose $=$ pesquisa-academica $>$. Acesso em: 25 jan 2009.

DAVINI, M.C. Enfoques, problemas e perspectivas da Educação Permanente de Recursos Humanos em Saúde. In: BRASIL. Ministério da Saúde. Secretaria de Gestão do Trabalho e Educação em Saúde. Politica Nacional de Educação Permanente. Brasilia: SGTES, 2009. p.39-58.

DIAS, P. Comunidades de aprendizagem na Web. Inovação, v.14, n.3, p.27-44, 2001.

FRÓES BURNHAM, T. et al. Ambientes virtuais de aprendizagem na formação de formadores em educação a distância. In: VALENTE, V. R. et al. (Orgs.). Educação à distância e ambientes virtuais de aprendizagem: uma troca de experiência Luso Brasileira. Salvador; Universidade do Estado da Bahia, 2007. Disponível em: <http:// www.comunidadesvirtuais.pro.br/coloquiolusobrasileiro/07.pdf >. Acesso em: 6 jun. 2012.

LÉVY, P. Cibercultura. São Paulo: Ed. 34, 1999.

MORIN, E. Ciência com consciência. Tradução Maria D. Alexandre e Maria Alice Sampaio Dória. 2.ed. Rio de Janeiro: Bertrand Brasil, 1998.

PRETTO, N.L. Uma escola sem/com futuro. São Paulo: Papirus, 1996.

RIBEIRO, E.C.O.; MOTTA, J.I.J. Educação permanente como estratégia na reorganização dos serviços de saúde. Divulg. Saude Debate, n.12, p.39-44, 1996.

TAPSCOOT, D. A hora da geração digital: como os jovens que cresceram usando a internet estão mudando tudo, das empresas aos governos. Tradução Marcelo Lino. Rio de Janeiro: Agir Negócios, 2010.

UNIVERSIDADE FEDERAL DA BAHIA. Instituto de Saúde Coletiva. Relatório final do curso de Especialização em Saúde Coletiva com Concentração em Gestão Pública Municipal. Salvador: UFBA, 2010. 
Analisa-se a experiência do Curso de Especialização em Saúde Coletiva: concentração em Gestão Pública Municipal, desenvolvido no estado da Bahia, Brasil, visando qualificar gestores do SUS, mediante a política de Educação Permanente em Saúde (EPS). A Net-Escola de Saúde Coletiva desenvolveu a concepção e operacionalização do curso, articulando pressupostos da Educação a Distância à EPS, orientando-se por competências necessárias à gestão do SUS, para fortalecer projetos e ações que integram educação e trabalho. Desenvolveu-se entre 2009 e 2010, com cento e cinquenta vagas voltadas a gestores municipais de saúde e suas equipes, com base na interação todos-todos e na construção do conhecimento colaborativo, reforçando-se a autonomia e a autoria dos sujeitos, por meio da interatividade no ambiente virtual de aprendizagem, visando potencializar a formação de redes de aprendizagem colaborativa. Analisa-se como a estratégia pedagógica se desenvolveu, delineando-se os desafios enfrentados no processo de ensino-aprendizagem.

Palavras-chave: Redes de aprendizagem. Educação a distância. Educação continuada. Qualificação de gestão.

Collaborative learning networks: the contribution of distance education in the
qualification process for managers of the Brazilian National Health System - SUS

This paper examines the experience of the specialization course in Public Health: major in Municipal Public Management, developed in the state of Bahia, Northeastern Brazil, in order to qualify managers of Sistema Único de Saúde (SUS - National Health System) according to the Continuing Health Education policy. Net-Escola de Saúde Coletiva developed the course design and operation, articulating the presuppositions of Distance Education and Continuing Health Education, guided by the competencies that are necessary to manage the SUS in order to strengthen projects and activities that integrate education and work. The course was developed between 2009 and 2010, with 150 places for municipal health managers and their teams, based on the all-all interaction and on the construction of collaborative knowledge. It strengthened the subjects' autonomy and authorship, by means of interactivity in the virtual learning environment, aiming to develop collaborative learning networks. This study analyses how the teaching strategy was developed, outlining the challenges faced in the teaching and learning process.

Keywords: Learning networks. Distance education. Continuing education. Management qualification.

Redes de aprendizaje de colaboración: contribución de la educación a distancia en la calificación de administradores del SUS

Se analiza la experiencia del Curso de Especialización en Salud Colectiva, concentración en Gestión Pública Municipal, desarrollado en el estado de Bahia, Brasil, con el objeto de calificar a administradores del Sstema Único de Salud brasileño (SUS), mediante la política de Educación Permanente en Salud (EPS). La Ned-Escuela de Salud Colectiva ha desarrollado este curso articulando presupuestos de la Educación a Distancia. Su orientación se apoya en las competencias necesarias a la gestión del SUS para fortalecer proyectos y acciones que integran educación y trabajo. En 2009 y 2010 ha contado con 150 puestos dedicados a adminstradores municipales de salud construyendo conocimiento de colaboración y reforzando autonomía y autoría de los sujetos por medio de la actividad en el ambiente virtual del aprendizage para potenciar la formación de redes de colaboración. Se analizan también el desarrollo de la estrategia pedagógica y los desafíos del proceso.

Palabras clave: Redes de aprendizaje. Educación a distancia. Educación continua. Calificación de gestión. 
